\title{
Pathfinding by Identified Growth Cones in the Spinal Cord of Zebrafish Embryos
}

\author{
John Y. Kuwada, ${ }^{1,2,3}$ Robert R. Bernhardt, ${ }^{1}$ and Ajay B. Chitnis ${ }^{1,2}$ \\ 'Department of Biology, ${ }^{2}$ Neuroscience Program, and Institute of Gerontology, University of Michigan, Ann Arbor, \\ Michigan 48109
}

The spinal cord of early (18-20 hr) zebrafish embryos consists of a small number of neurons per hemisegment. The earliest neurons are identified and project growth cones that follow stereotyped, cell-specific pathways to reach their termination sites. We have studied the pathways taken by 4 of the early neurons in order to delineate the cells and structures their growth cones encounter during pathfinding. These neurons are 3 classes of commissural neurons (CoPA, CoSA, and $(\mathrm{Co})$, which have contralateral longitudinal axons, and the VeLD neuron, which has an ipsilateral longitudinal axon.

These growth cones encounter a defined set of cells and structures. Commissural growth cones appear to bypass the longitudinal axons of several identified neurons, including those from contralateral commissural neurons they encounter immediately following projection from the cell bodies. In contrast, these growth cones appear to extend in association with the longitudinal axons of commissural cells after crossing the ventral midline. Another set of cells of interest are the floor plate cells, a row of cells that constitute the ventral floor of the cord. At the floor plate growth cones exhibit cellspecific behaviors which may be influenced by the floor plate. (1) The floor plate may attract specific growth cones. The CoPA, CoSA, CoB, and VeLD growth cones all extend to the floor plate while other identified growth cones do not. (2) The floor plate may mediate cell-specific turns and induce some growth cones to cross the midline while inhibiting others from doing so. The commissural growth cones extend directly under the floor plate to cross the midline and turn anterior (CoPA and CoSA) or bifurcate (CoB); the VeLD growth cone turns away from the midline and extends posteriorly. (3) The floor plate may mediate changes in the substrate affinities of growth cones. Commissural growth cones bypass longitudinal pathways before they have encountered the floor plate, but not after.

The description of pathfinding by these growth cones suggests that some elements in their environment are ignored while others are not. Most interestingly, a single structure (the floor plate) may mediate multiple, cell-specific effects on spinal growth cones.

\footnotetext{
Received July 20, 1989; revised Oct. 16, 1989; accepted Oct. 23, 1989.

We thank G. Piperno for the antibody against acetylated tubulin, $P$. Knafl for technical assistance, and $\mathrm{K}$. Tosney for critically reading the manuscript. This work was supported by grants from NIH (NS24848), Office of the Vice-President for Research at the University of Michigan, and a Basil O'Connor Scholar Award from the March of Dimes Birth Defects Foundation to J.Y.K.

Correspondence should be addressed to Dr. John Y. Kuwada, Institute of Gerontology, University of Michigan, 300 N. Ingalls, Ann Arbor, MI 48109-2007.

Copyright (C) 1990 Society for Neuroscience $0270-6474 / 90 / 041299-10 \$ 02.00 / 0$
}

The CNS of early fish embryos is an especially attractive system to study mechanisms of axonal guidance (Eisen et al., 1986, 1989; Kuwada, 1986; Chitnis and Kuwada, 1990; R. R. Bcrnhardt, A. B. Chitnis, and J. Y. Kuwada, unpublished observations; J. Y. Kuwada, R. R. Bernhardt, and N. Nguyen, unpublished observations). The embryonic spinal cord consists of approximately 18 neurons per hemisegment at $18-20 \mathrm{hr}$ of development. By $18 \mathrm{hr} \mathrm{8-11}$ of these early neurons have projected growth cones and fall into 6 classes of identified neurons. These are approximately 3 mechanosensory Rohon-Beard (RB) neurons, usually 1 primary commissural interneuron (CoPA), 0-2 secondary commissural interneurons (CoSA), at most a single dorsal longitudinal interneuron (DoLA), usually 1 ventral longitudinal interneuron (VeLD), and 3 primary motor neurons (CaP, MiP, and RoP). Thus, the growth cones of these early neurons face an environment consisting of only a small number of identified neuronal somata and axons. Within this simple neuronal environment these growth cones follow cell-specific pathways to reach their targets (Kuwada et al., unpublished observations). In the embryonic cord of the Japanese medaka fish laser ablation of cells suggests that pathfinding in the spinal cord involves highly specific cell-cell interactions (Kuwada, 1986).

Axonogenesis in the early cord shares some features with axonogenesis in the other systems. In the grasshopper CNS the carlicst growth cones follow cell-specific pathways within an extremely simple environment consisting of identified neuronal and non-neuronal cells (Goodman et al., 1984). Extensive experimental analyses have demonstrated the importance of both neuronal and non-neuronal cells for axonal guidance in the grasshopper CNS (Raper et al., 1984; Bastiani and Goodman, 1986; Bastiani et al., 1986; du Lac et al., 1986). In the spinal cord of rat embryos recent studies have implicated an important role for identifiable non-neuronal cells, the floor plate cells, for axonal guidance (Dodd and Jessell, 1988; Tessier-Lavigne et al., 1988). Likewise, non-neuronal cells may be significant for pathfinding in the embryonic fish cord. In Japanese medaka embryos the pathway taken by the earliest RB growth cones essentially consists of other RB cells and the endfeet processes of dorsal neuroepithelial cells. Pathfinding by these growth cones does not require other $\mathrm{RB}$ neurons, leaving open the possibility that the longitudinally arrayed endfeet of dorsal neuroepithelial cells may be important (Kuwada, 1986). Here we describe the neuronal and non-neuronal cells encountered by the CoPA, CoSA, and VeLD growth cones in order to identify cells that may potentially provide guidance cues.

\section{Materials and Methods}

Animals. Zcbrafish cmbryos were collcctcd from a laboratory breeding colony and maintained according to the procedures described in Myers 


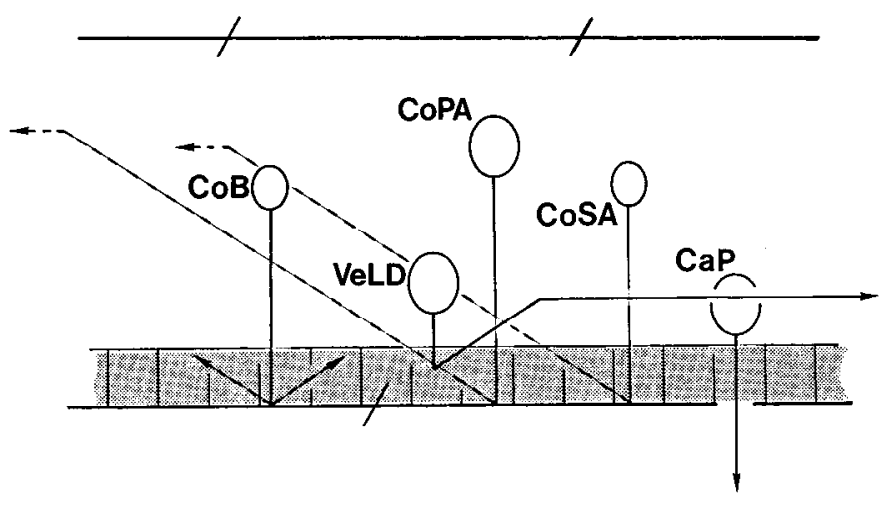

Figure 1. Schematic diagram showing the axonal trajectories of some of the early spinal neurons and the floor plate cells. The relative sizes and locations of the cell bodies are indicated. The positions of the CoPA, $\mathrm{CoSA}$, and $\mathrm{CoB}$ cells along the anterior/posterior axis are not stereotyped. Floor plate cells (gray, dashed lines) signify contralateral axons, and arrows indicate that axons extend beyond the diagram. Segment borders (diagonal lines) are defined by the boundaries of the metamerically organized axial muscles found lateral to the cord.

et al. (1986). Embryos were kept at $28.5^{\circ} \mathrm{C}$ and staged from the estimated time of fertilization.

Lucifer yellow injections. Embryos were dissected to remove their yolk sacs, fixed for $6-10$ min in $2-4 \%$ paraformaldehyde and $1 \%$ dimethyl sulfoxide (DMSO) in $75 \mathrm{~mm}$ phosphate buffer ( $\mathrm{pH} 7.4$ ), washed, pinned in a Sylgard (Dow Corning) lined embryo holder, and placed on a fixed-stage Zeiss compound microscope outfitted with differential interference contrast (DIC) optics and epifluorescence. Neuronal somata were visualized with DIC optics, impaled with microelectrodes filled with $10 \% \mathrm{LY}$ in distilled water, and filled with dye by injecting hyperpolarizing currents $(0.1-0.5 \mathrm{nA}$ for $10-120 \mathrm{sec})$. Labeled neurons were then photographed, drawn with a camera lucida, or labeled with horseradish peroxidase (HRP) using the Lucifer yellow (LY) antiserum.

Antibody labeling. LY-injected neurons were in some cases marked with HRP reaction product by application of a rabbit antiserum to $L Y$ dye (Taghert et al., 1982). Following intracellular injections embryos were fixed in $2-4 \%$ paraformaldehyde and $1 \%$ DMSO in phosphate buffer for $30 \mathrm{~min}$; washed in buffer; immersed in $0.5-1 \%$ collagenase (Sigma, Type 1A) in phosphate buffer for 3-5 min; washed; and incubated in 1:500 dilution of LY antiserum with $0.5-1 \%$ Triton $X-100$, $0.5-1 \% \mathrm{BSA}$, and $0.5-1 \%$ normal goat serum in phosphate buffer overnight at $5^{\circ} \mathrm{C}$. Embryos were then washed; incubated in 1:250 dilution of HRP-conjugated goat anti-rabbit with $0.5-1 \%$ Triton X-100, $0.5-1 \%$ BSA, and $0.5-1 \%$ normal goat serum overnight at $5^{\circ} \mathrm{C}$ or for $3-5 \mathrm{hr}$ at $33^{\circ} \mathrm{C}$; washed; incubated in diaminobenzidine $(0.5 \mathrm{mg} / \mathrm{ml})$ for $20 \mathrm{~min}$; and reacted by adding hydrogen peroxide. In some cases antibodylabeled embryos were refixed, dehydrated, embedded in plastic, and sectioned (1- $\mu \mathrm{m}$ semithins).

Embryos were labeled with a monoclonal antibody against acetylated tubulin (Piperno and Fuller, 1985) as wholemounts by following the procedures for wholemount labeling described in Patel et al. (1989). Embryos were labeled with the anti-CON1 monoclonal antibody by the anti-LY procedure with the exception of using an HRP-conjugated antimouse as the secondary antibody.

Electron microscopy. Embryos were processed for electron microscopy (EM) by fixing in 3\% glutaraldehyde, $2 \%$ paraformaldehyde, $1 \%$ acrolein, and $1 \%$ DMSO in $75 \mathrm{~mm}$ phosphate buffer for $1 \mathrm{hr}$; washed; postfixed in $2 \%$ osmium tetroxide in phosphate buffer for $2 \mathrm{hr}$; washed in $50 \mathrm{~mm}$ sodium maleate buffer ( $\mathrm{pH} 5.9$ ); stained with $2 \%$ uranyl acetate in maleate buffer for 1-2 hr; washed in maleate buffer; dehydrated in an ethanol and propylene oxide series; embedded in plastic; and thinsectioned.

Histogram construction. Histograms were constructed to determine if the position along the anterior/posterior axis of the ventrally directed portion of the axons of early commissural cells coincided with the positions of the CaP or VeLD neurons. All neurons were labeled with the acetylated tubulin antibody and drawn with a camera lucida in five 18$\mathrm{hr}$ embryos. For each embryo the average segment length (distance between consecutive $\mathrm{CaPs}$ ) and average $\mathrm{CaP}$ diameter for segments 5-
9 was determined. The average segment length and standard deviation for all 5 embryos was $52 \pm 5.9 \mu \mathrm{m}$. The average CaP diameter for all 5 embryos was $8.8 \pm 0.9 \mu \mathrm{m}$. Since the $\mathrm{CaP}$ cell body was approximately $1 / 6$ of the segment length, $1 / 6$ of the segment length was defined as a bin unit, and the distance along the anterior/posterior axis between the ventrally directed portion of the early commissural axons and the center of the nearest CaP or VeLD neuron was determined in bin units. This data was compiled as histograms. Since there is normally a single $\mathrm{CaP}$ (Myers et al., 1986) and a single VeLD soma per hemisegment at $18 \mathrm{hr}$ (Kuwada et al., unpublished observations), a commissural axon would be no farther than 3 bin units (half the segment length) from the nearest CaP or VeLD.

\section{Results}

The behavior of identified growth cones and the cells and structures they encounter in the simple spinal cord of zebrafish embryos (Fig. 1) have been delineated from a variety of sources. These include intracellular LY injections (89 CoPAs at 16-20 $\mathrm{hr} ; 44$ VeLDs at $16-17 \mathrm{hr} ; 133 \mathrm{CoSAs}$ at $18-28 \mathrm{hr} ; 19 \mathrm{CoBs}$ at 22-28 hr), application of the acetylated tubulin antibody (Piperno and Fuller, 1985) to wholemounted embryos $(n=10,18$ hr) to label many of the embryonic neurons (Bernhardt et al., unpublished observations; Chitnis and Kuwada, 1990), and application of the anti-CON1 antibody ( $n=25,28-36 \mathrm{hr}$ ), which labels the RB and CoPA neurons in the early embryonic cord (Kuwada et al., 1987).

Often when neuronal somata are impaled with LY-filled electrodes, the adjacent neuroepithelial cells become labeled through their endfeet processes which overlie the neuronal somata (see, for example, Figs. $3 B, 4$ ). The labeled neuroepithelial cells are probably not a result of dye coupling since the embryos are fixed prior to injections (see Materials and Methods). Furthermore, we have confirmed that the filled structures adjacent to the neuronal somata are not part of the neuron by backfilling neurons with diI and by labeling neurons with the acetylated tubulin and anti-CON1 antibodies (Bernhardt et al., unpublished observations; Kuwada et al., unpublished observations). The antiCON1 antibody labels the dendrites, cell body, axon, and growth cone of the RB and CoPA neurons in early embryos.

\section{Floor plate cells}

The floor plate cells are a row of cells along the anterior/posterior axis, approximately 3 cells wide, that make up the ventral floor of the early cord (Fig. 2). These are prominent cells that are readily identified as rectangular cells at the ventral floor of the cord in side views of embryos with DIC optics. Electron micrographs of early cords showed that these cells are triangular in cross section, with one cell in the middle that straddles the ventral midline and usually one cell lateral to the middle cell on both sides. There are approximately 20 floor plate cells per segment at $18 \mathrm{hr}$ of development.

The floor plate cells are among the first cell types discernible in the embryonic cord and can be seen as early as $14 \mathrm{hr}$ in development in the midtrunk segments (data not shown). This is before the earliest spinal growth cones are projected (Kuwada et al., unpublished observations). Accordingly, in the tail bud of older embryos the floor plate cells are evident just as soon as the cord and the notochord are discernible (Fig. $3 \mathrm{~A}$ ).

The floor plate cells are presumably non-neuronal cells. LY injections confirmed that the floor plate cells are rectangularshaped when seen in side views, with no processes at lcast up to $28 \mathrm{hr}$ of development (Fig. 3B). Furthermore, unlike most neurons, which do not contact the lumenal basal lamina, the floor plate cells contact the basal laminae on both the lumenal and superficial sides of the cord (Fig. $2 B$ ) much like neuroepithelial 

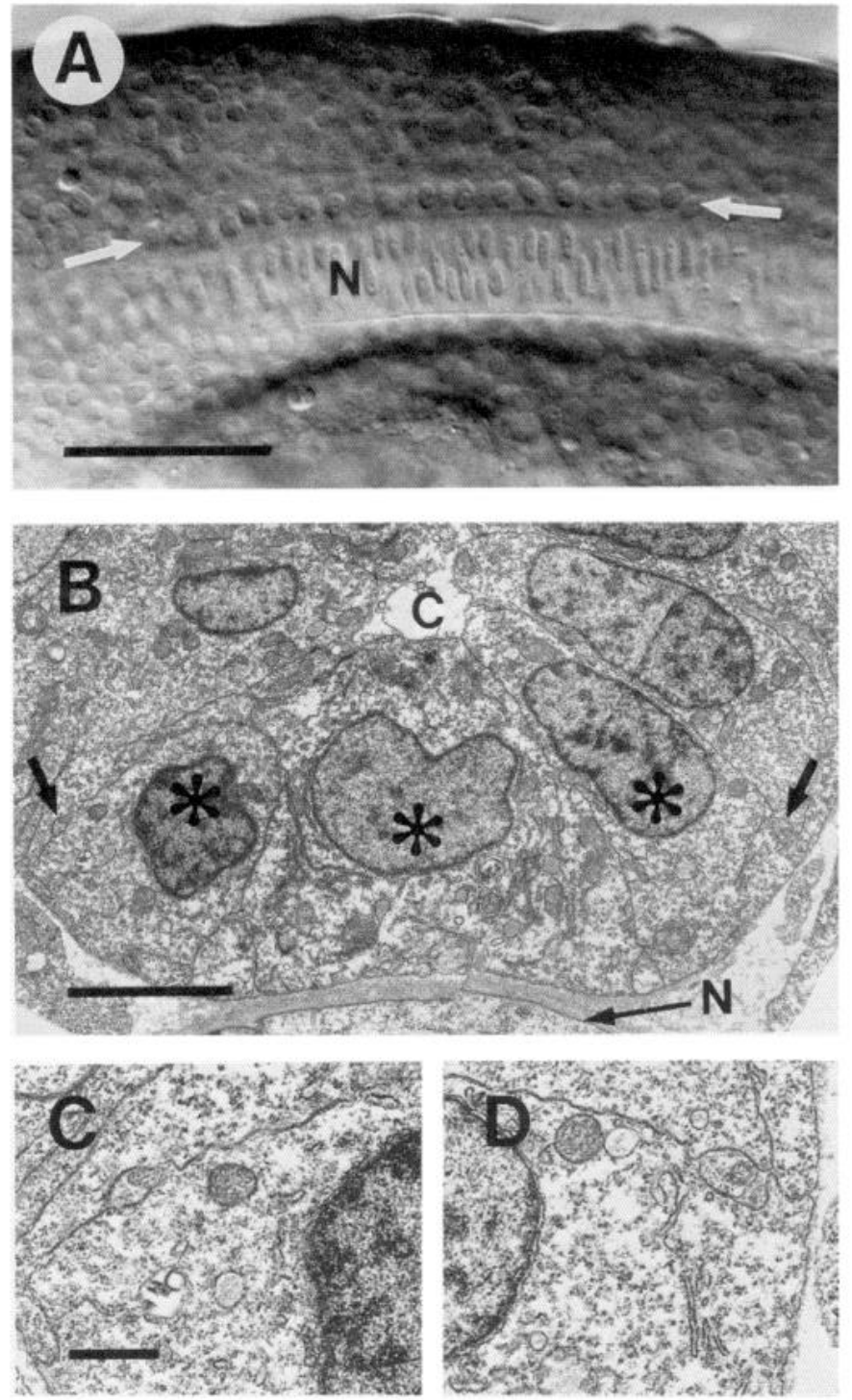

Figure 2. Floor plate cells are identified cells that make up the ventral floor of the early cord. $A$, DIC micrograph of the middle row of floor plate cells (arrows) from a live 17-hr embryo. This and all subsequent figures show side views of the cord with anterior to the left and dorsal up unless otherwise noted. $N$, Notochord; scale, $50 \mu \mathrm{m}$. $B$, EM micrograph of the floor plate cells (asterisks) in cross section from a $20-\mathrm{hr}$ embryo. Arrows point to 2 axonal profiles, which may represent VeLD axons, in contact with the lateral floor plate cells (see text). $C$, Central canal; $N$, notochord; scale, $5 \mu \mathrm{m}$. $C$ and $D$, Detail of the axons marked by the arrows in $B$. Scale, $1 \mu \mathrm{m}$.

cells. However, floor plate cells differ from typical neuroepithelial cells: neuroepithelial cells are spindle-shaped in cross section and extend endfeet processes, which extend laterally from the soma and expand into foot-shaped endings that contact the superficial basal lamina (Kuwada, 1986; Kuwada et al., unpublished observations); floor plate cells are triangular in cross section and do not extend endfeet processes.

Identified growth cones behave in cell-specific ways at the floor plate cells

The CoPA and VeLD neurons (Fig. 4) are 2 of the earliest neurons in the embryonic cord (Bernhardt et al., unpublished observations; Kuwada et al., unpublished observations). The
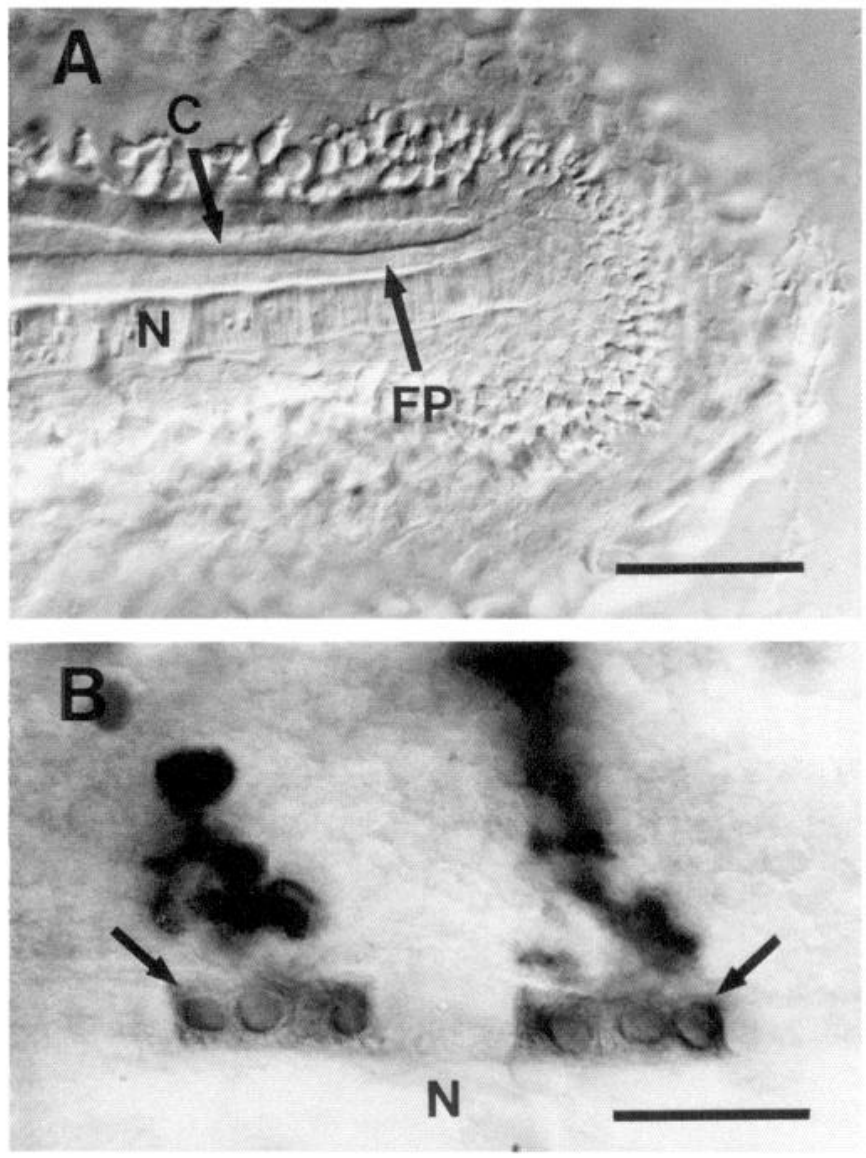

Figure 3. Floor plate $(F P)$ cells are among the earliest cells in the cord and do not develop processes. $A$, DIC micrograph of the tail bud of a $23-\mathrm{hr}$ embryo. Floor plate cells are distinguishable as soon as the notochord $(N)$ is distinguishable. $C$, Central canal; scale, $50 \mu \mathrm{m} . B, \mathrm{LY} /$ anti-LY-labeled floor plate cells (arrows) are rectangular in a 28 -hr embryo. Neuroepithelial cells dorsal to the floor plate cells in the path of the dye-filled electrode are also labeled (see text). $N$, Notochord; scale, $25 \mu \mathrm{m}$.

CoPA neuron is a commissural neuron with an ascending longitudinal axon in the dorsal longitudinal fasciculus (DLF) contralateral to its soma; the VeLD neuron has a descending longitudinal axon in the ventral longitudinal fasciculus ipsilateral to its soma. At $18 \mathrm{hr}$ there are usually one CoPA and one VeLD neuron per hemisegment. The CoPA soma is found in the dorsolateral region of the cord, while the VeLD cell body is located dorsal to the primary motor neurons and approximately halfway between consecutive $\mathrm{CaP}$ motor neurons in the ventrolateral region of the cord (Kuwada et al., unpublished observations). Despite the fact that the VeLD neuron has primarily an ipsilateral longitudinal axon, both it $(n=22)$ and the CoPA neuron $(n=19)$ initially project ventrally directed growth cones from the ventral poles of their cell bodies at 16-17 hr of development (Fig. 4, $C, D$ ). Both growth cones extend along the circumference of the cord to the floor plate cells (CoPA, $n=30$; VeLD, $n=$ 22; Fig. 4).

At the floor plate the growth cones of the CoPA and VeLD neurons change their pathfinding behavior, but in cell-specific ways. Horizontal sections of cords with LY/anti-LY-labeled CoPA growth cones $(n=8)$ showed that the CoPA growth cone crosses the ventral midline by extending directly under the floor plate cells (Fig. $5 A$ ). This probably occurs by the growth cone inserting between the floor plate cells and the ventral basal lam- 
Figure 4. CoPA and VeLD growth cones follow cell-specific pathways but both are initially ventrally directed. $A$, Fluorescence micrograph of an LY-filled CoPA neuron with a growth cone just past the ventral midline from a 19-hr embryo. This is a photomontage that displays the soma and the contralateral growth cone, which are at different focal planes, simultaneously. Arrow, Point where the axon crosses the ventral midline; dashed line, dorsal border of the cord; ventral border of the cord is the faint line just ventral to the growth cone. $B$, LY-filled VeLD neuron from a 17 hr embryo. LY-filled cells posterior and dorsal to VeLD cell body (asterisk) are neuroepithelial cells that are inadvertently filled during neuronal impalements (see text). Dashed lines, Dorsal and ventral borders of the cord. Scale for $A$ and $B, 50 \mu \mathrm{m}$. $C$, Camera lucida drawing of an LY-filled CoPA neuron in a 17-hr embryo. Cord is outlined; diagonal lines, segment borders. D, Camera lucida drawing of an LY-filled VeLD neuron in a 16-hr embryo. Scale for $C$ and $D, 50 \mu \mathrm{m}$.
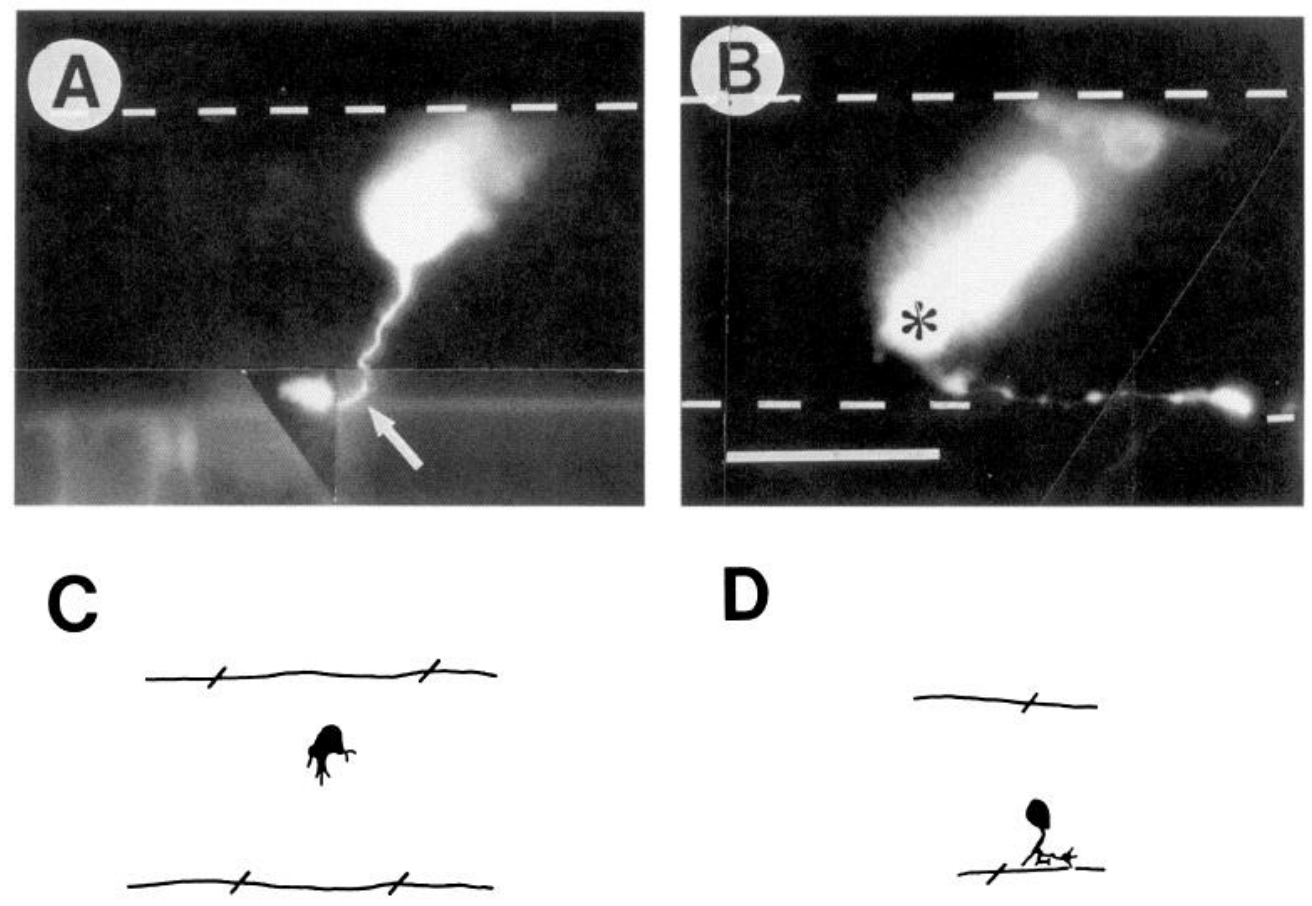

ina (Kuwada et al., unpublished observations), while under the floor plate or just past the contralateral, lateral floor plate cell, the CoPA growth cone makes a turn in the anterior direction (Fig. 5B). This leaves behind commissural axons ventral to the floor plate cells.

In contrast to the CoPA growth cone, the VeLD growth cone extends to the floor plate but remains ipsilateral, turns posteriorly, and extends caudally near the lateral floor plate cells ( $n$ $=3$; Fig. 6). In concordance with this, longitudinal axons, which are likely to be VeLD axons or the longitudinal portions of the axons of the primary motor neurons (Myers et al., 1986), are seen in contact with the floor plate at $20 \mathrm{hr}$ (Fig. 2, B-D). At this time the only longitudinal axons found in the ventral cord are those of the VeLD and primary motor neurons. Interestingly, just as the VeLD growth cone is turning, the proximal part of the growth cone remains as broad as the leading edge (Fig. 6A). The proximal portion of the growth cone presumably represents the portion of the growth cone that was initially projected toward the floor plate.

The behavior of growth cones of certain neurons, which undergo axonogenesis 2-8 hr after the CoPA and VeLD neurons (Bernhardt et al., unpublished observations; Kuwada et al., unpublished observations), also correlates with the floor plate cells. The CoSA neuron has an axonal trajectory similar to that of the CoPA neuron, and the $\mathrm{CoB}$ neuron is a commissural neuron with both ascending and descending axons in the ventrolateral cord contralateral to its cell body (Bernhardt et al., unpublished observations). They are located in the dorsal cord and extend growth cones ventrally to the floor plate and ventral midline (CoSA, $n=31$; $\mathrm{CoB}, n=15)$ at stages following the CoPA and VeLD growth cones. Under or immediately past the floor plate these growth cones make cell-specific turns (Fig. 7). The CoSA growth cone turns anterior to follow a rostrodorsal pathway (see below), while the $\mathrm{CoB}$ growth cone bifurcates to extend growth cones both rostrally and caudally in the ventral cord.
These results demonstrate that the floor plate is the site of numerous cell-specific behaviors by identified growth cones in the spinal cords of zebrafish embryos. Some growth cones (CoPA, $\mathrm{CoSA}, \mathrm{CoB}$, and VeLD) extend toward the floor plate; a subset of these (CoPA, CoSA, and $\mathrm{CoB}$ ) cross the ventral midline by extending under the floor plate while the VeLD growth cone remains ipsilateral; each growth cone makes a cell-specific turn at the floor plate.

\section{Pathfinding by commissural growth cones is not correlated with the positions of the cell bodies of identified ventral neurons}

In principle all of the behaviors exhibited by commissural growth cones could be due to interactions with cells found in the ventral cord. The previous section demonstrated that the floor plate cells are correlated with the cell-specific actions of commissural and VeLD growth cones. In addition to the floor plate cells, the ventral cord of early zebrafish embryos contains a small number of identified neurons (Bernhardt et al., unpublished observations) which may potentially affect commissural growth cones. At $18 \mathrm{hr} 2$ neurons that are unequivocably identifiable, based on their early axon trajectories, are the CaP primary motor neuron (Myers et al., 1986) and the VeLD interneuron. To determine whether these ventral neuronal cell bodies are in the normal pathway of the commissural growth cones, we plotted the position of the cell body along the anterior/posterior axis of each identified neuron (CaP and VeLD) nearest to the ventrally directed portion of the commissural axon in 18-hr embryos. In these embryos a monoclonal antibody against acetylated tubulin (Piperno and Fuller, 1985) was used to label embryonic neurons in the zebrafish (Chitnis and Kuwada, 1990).

If the commissural growth cones were attracted by the $\mathrm{CaP}$ or VeLD cell bodies, one might expect the proximal portions of the commissural axons to overlap with the CaP or VeLD cell 

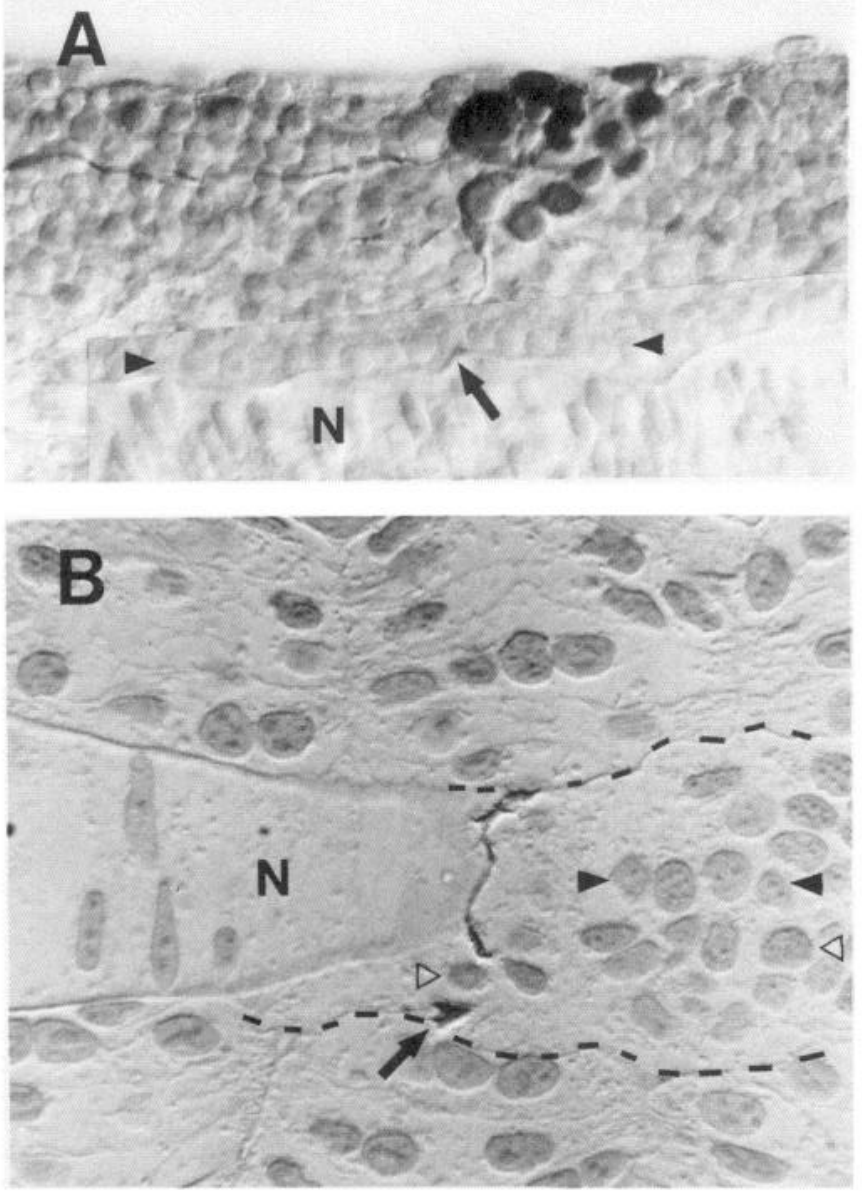

Figure 5. CoPA growth cones extend under the floor plate cells and turn anterior. $A$, Photomontage of an LY/anti-LY-labeled CoPLA growth cone (arrow) pointing anteriorly under the floor plate cells (arrowheads) in an 18-hr embryo. Photomontage was constructed to show the CoPA cell body and growth cone at the same time. The large neuron just dorsal to the CoPA cell body is an RB cell. $N$, Notochord. $B$, Horizontal section showing that an LY/anti-LY-labeled CoPA growth cone (arrow) has turned anterior just past the lateral row of floor plate nuclei (open triangles) in an 18-hr embryo. The CoPA axon can be seen crossing the floor of the cord in the middle of the micrograph. A gap between the axon and growth cone appears because the portion of the axon just proximal to the growth cone was located in an adjacent section. On the left this section passed through the underlying notochord $(N)$. Axial muscles are on either side of the cord. Arrowheads, Middle floor plate cells and ventral midline; dashed lines, lateral borders of the ventral cord. Scale for $A, 50 \mu \mathrm{m}$; scale for $B, 25 \mu \mathrm{m}$.

bodies. This, however, is not the case for the early commissural cells (both CoPA and the earliest CoSAs; Fig. 8). The position of neither the CaP nor the VeLD somata nearest the commissural ventral axon was not significantly different from that expected if no relationship existed $\left(\chi^{2}\right.$ test, for CaP: $\chi^{2}=0.2, d f$ $=2, p<0.5$; for VeLD: $\chi^{2}=0.8, d f=2, p<0.5$ ). Since the $\mathrm{CaP}$ and VeLD somata are randomly distributed with respect to the proximal axon of the early commissural neurons, pathfinding by commissural growth cones is probably independent of these somata. This is likely to be true even if the CaP and VeLD somata are considered in combination since they are found in stereotyped positions in the spinal segments (Myers et al., 1986; Bernhardt et al., unpublished observations).
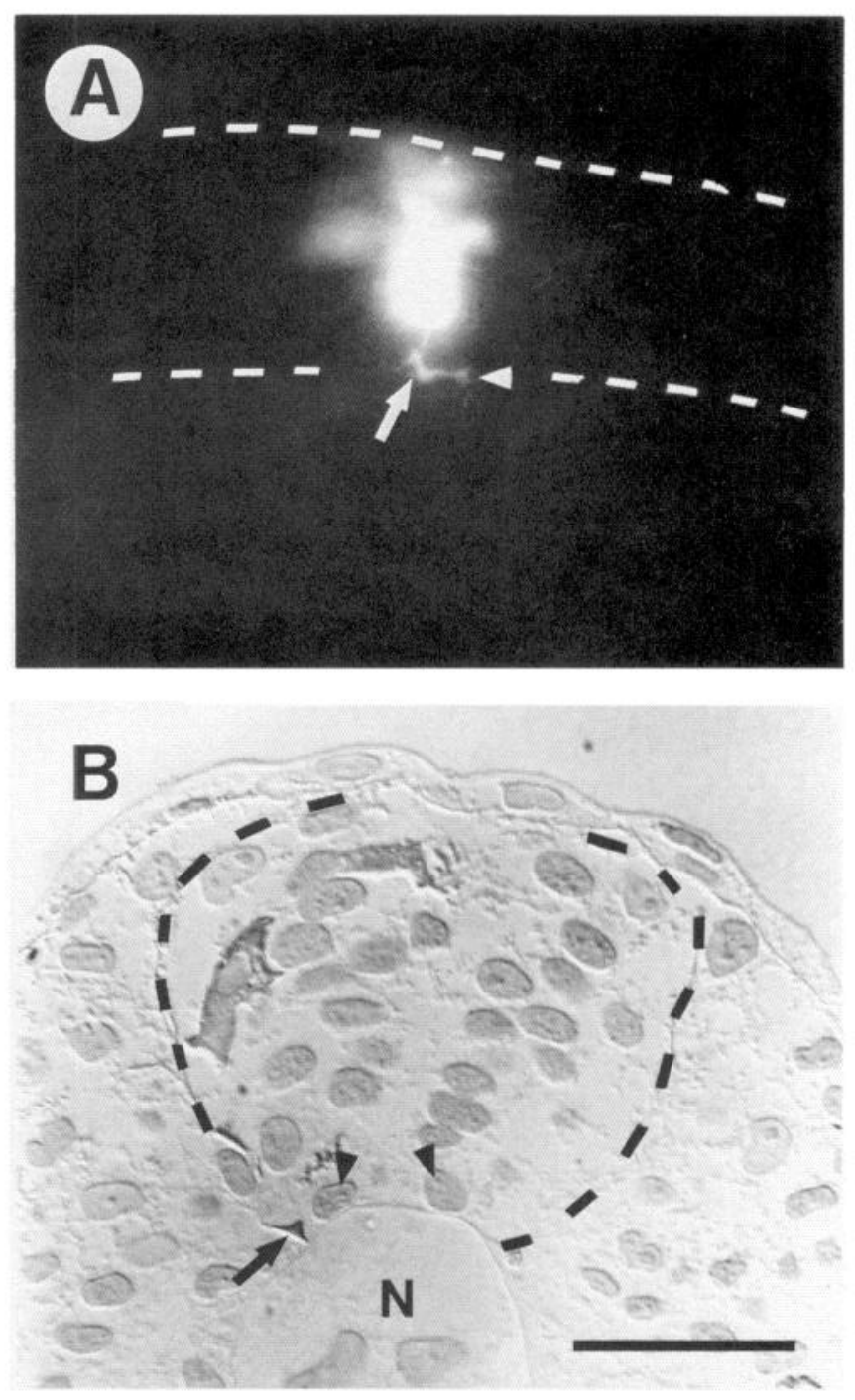

Figure 6. VeLD growth cone extends to the floor plate cells and turns and extends posteriorly along the floor plate cells. $A$, Fluorescence micrograph of an LY-filled VeLD growth cone that has just turned posterior at the ventral floor of the cord in a 16-hr embryo. Arrowhead, Leading edge of the growth cone; arrow, proximal part of the growth cone; dashed lines, dorsal and ventral outline of the cord. $B$, Cross section showing the LY/anti-LY-labeled VeLD growth cone (arrow) extending posteriorly along the lateral floor plate cells (arrowheads denote their nuclei) in a 17-hr embryo. The nucleus of a middle floor plate cell was not in this section. There is a lightly labeled unidentified neuron dorsal to the VeLD growth cone. Dashed lines, Lateral borders of the cord; $N$, notochord. Scale for $A, 50 \mu \mathrm{m}$; scale for $B, 25 \mu \mathrm{m}$.

\section{Commissural growth cones appear to bypass some cells and structures but not others}

The CoPA growth cone initially extends ventrally along a circumferential pathway (Kuwada et al., unpublished observations). One way the direction of outgrowth may be explained is if the CoPA growth cone is physically blocked from extending longitudinally but not circumferentially. Longitudinal barriers are unlikely since other dorsal neurons encounter no such barriers. First, RB growth cones extend longitudinally in the vicinity of the CoPA cell body prior to or at the time of emergence of the CoPA growth cone (Fig. $9 A$ ). Second, DoLA neurons project ascending growth cones in the immediate vicinity of CoPA neurons (Fig. 9B). 

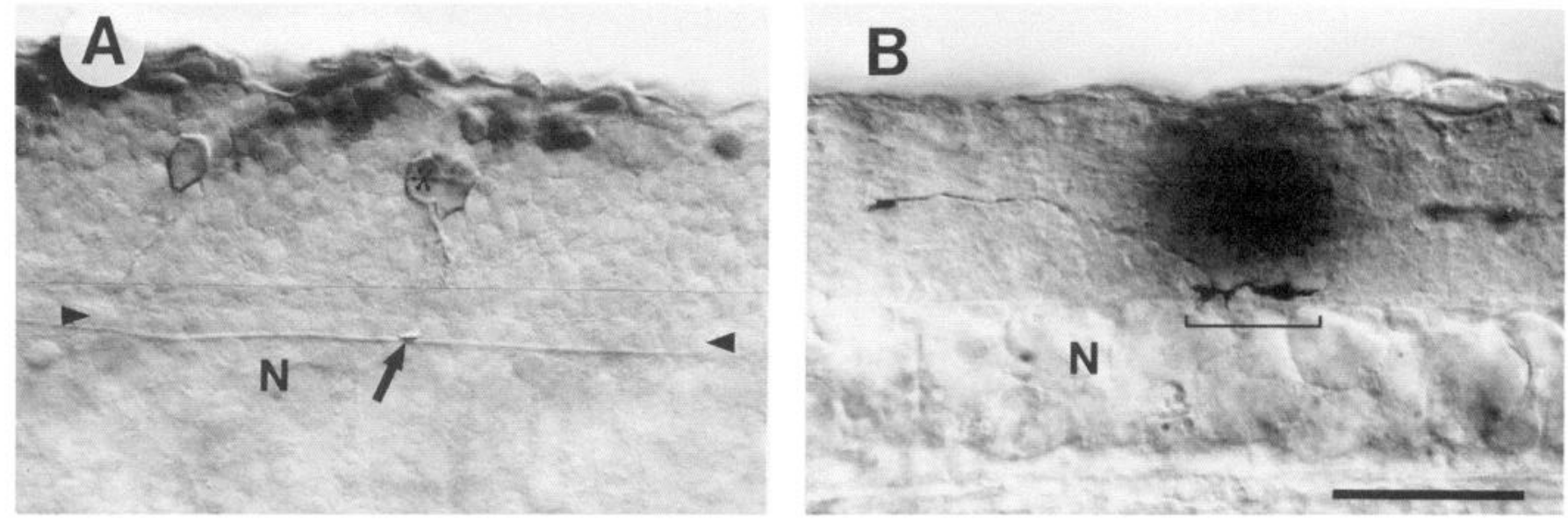

Figure 7. Neurons that begin axonogenesis following the earliest neurons extend to the floor plate. A, Photomontage of an LY/anti-LY-labeled CoSA growth cone (arrow) under the floor plate (arrowheads) in a 26-hr embryo. This montage was constructed to show the cell body (asterisk) and the labeled growth cone at the same time. Two other commissural neurons have also been labeled. $N$, Notochord. $B$, Growth cone (bracket) of a CoB neuron injected with HRP in a 26-hr embryo. The growth cone anterior and dorsal to the CoB growth cone is that of a CoSA neuron. The cell bodies of both neurons are out of focus. Scale for $A$ and $B, 50 \mu \mathrm{m}$.

Once early commissural growth cones are projected, they encounter a limited number of neuronal somata and axons which they appear to bypass during the early portion of their axonogenesis. First, CoPA growth cones bypass RB axons that course nearby (Fig. 9A). Second, CoPA and early CoSA growth cones appear to ignore the cell bodies of at least some of the neurons found in the ventral cord (CaP and VeLD neurons) since the trajectories of the ventrally directed portions of their axons are independent of them (see above; Fig. 8). Third, prior to reaching the floor plate CoPA growth cones often bypass the longitudinal axons of ipsilateral VeLD cells as they extend ventrally along a circumferential path (Fig. $9 \mathrm{C}$ ). After crossing the midline, CoPA growth cones bypass the longitudinal axons of contralateral VeLD cells as they extend in an oblique pathway running rostrodorsally (data not shown). Fourth, CoPA growth cones are apparently independent of the axons and growth cones of contralateral CoPA neurons. When all CoPA neurons are labeled with the anti-CON1 antibody (Kuwada et al., 1987), CoPA axons are often seen to intersect with their counterparts from the contralateral side near the ventral midline, indicating that they may contact each other during axonogenesis (data not shown). Apparently such contact with contralateral CoPA neurons is not necessary for pathfinding. Occasionally some hemisegments contain no CoPA neurons (Bernhardt et al., unpublished observations); in such cases the CoPA neuron in a contralateral hemisegment will extend an axon that will not intersect the axons of contralateral CoPA neurons. Despite this, these axons have normal trajectories (Fig. 10).

\section{Pathfinding by $\operatorname{CoSA}$ growth cones}

The CoSA neurons initiate axonogenesis some $2-8 \mathrm{hr}$ after the CoPA growth cones (the earliest at $18 \mathrm{hr}$ ). Growth cones are projected from the ventral poles of the CoSA somata and follow a stereotyped pathway similar to that of CoPA neurons (Fig. 11). The ventrally directed growth cones extend circumferentially to the floor plate cells, cross the ventral midline by extending under the floor plate, and turn anteriorly (Fig. 7A). They then extend obliquely along a rostrodorsal pathway to the DLF, where they turn longitudinally and ascend in the cord.

During pathfinding the CoSA growth cones appear to both
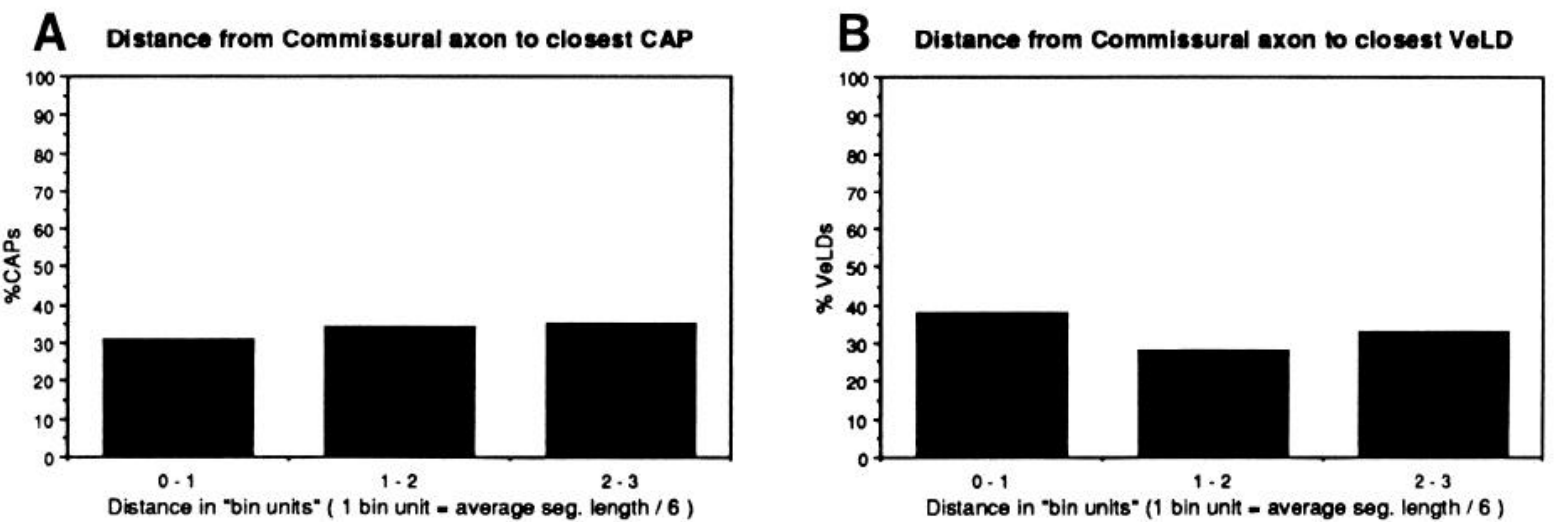

Figure 8. Trajectory of the ventrally directed portion of the axons of CoPA and the earliest CoSA neurons is not correlated with the position of the identified ventral neurons in 18 -hr embryos. $A$, Histogram showing the distance of the CaP soma nearest to the ventrally directed portion of the commissural neurons. A bin unit is approximately the diameter of the CaP soma (see Materials and Methods for details of histogram construction). This histogram was based on measurements from 71 commissural axon/CaP pairs. $B$, Histogram showing the distance of the VeLD soma nearest to the commissural axons. This histogram was based on 69 commissural axon/VeLD pairs. Neither histogram was significantly different from that expected from a random relationship between the commissural axons and ventral somata (see text). 


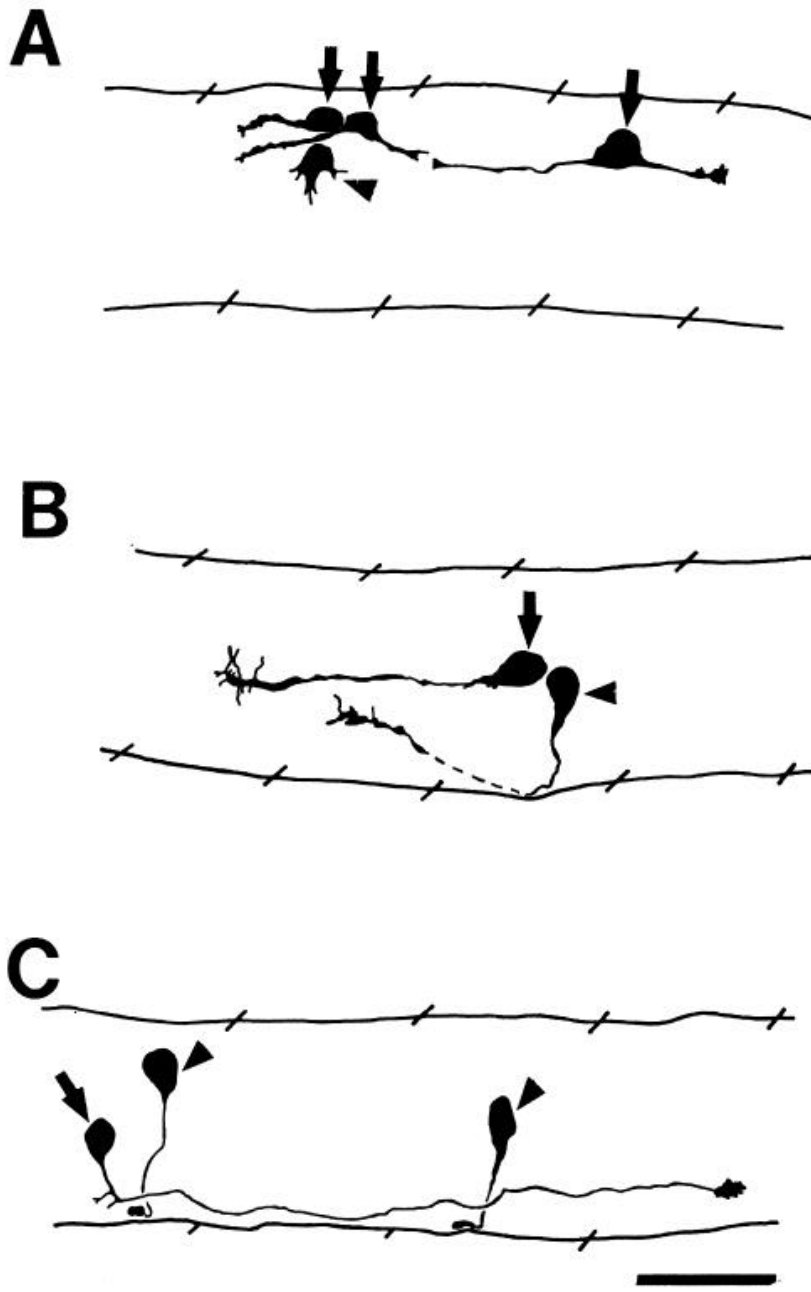

Figure 9. CoPA growth cones bypass the pathways of other identified growth cones. Camera lucida drawings of LY-filled neurons. A, RB (arrows) axons and growth cones are near a CoPA neuron (arrowhead) just projecting a growth cone at $17 \mathrm{hr}$. $B$, The growth cones of adjacent DoLA (arrow) and CoPA neurons follow cell specific pathways in a 20 hr embryo. $C$, Two CoPA growth cones have extended by the longitudinal axon of a nearby VeLD neuron (arrow) in a 19-hr embryo. Scale for all panels, $50 \mu \mathrm{m}$.

bypass and follow specific axons they encounter. To examine the relationship between the CoSA growth cone and other commissural axons, both CoSA and neighboring CoPA neurons were injected with $L Y(n=24, \mathrm{CoPA} / \mathrm{CoSA}$ pairs). Labeling of CoSA neurons just projecting growth cones and contralateral CoPA neurons $(n=3)$ demonstrated that CoSA growth cones bypass the longitudinal axons of contralateral CoPA neurons they encounter immediately upon emergence from the cell bodies (Fig. $12 A)$. This is in stark contrast to the behavior of CoSA growth cones with the longitudinal axons in the contralateral DLF. CoSA growth cones appear to extend in association with these longitudinal axons, which include the longitudinal axons of CoPA neurons (Bernhardt et al., unpublished observations). Furthermore, CoSA growth cones can be found in apparent association with the ventrally directed portion of nearby CoPA axons (Fig. $12 B$ ) as well as the rostrodorsal portion of the CoPA axon in the contralateral side (Bernhardt et al., unpublished observations). Additionally, since many CoSA neurons per hemisegment (Bernhardt et al., unpublished observations) project growth

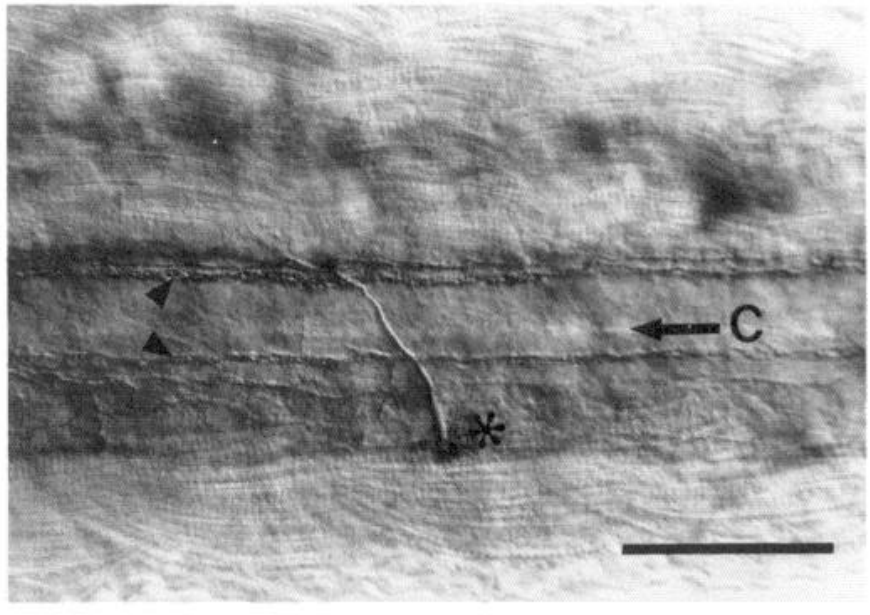

Figure 10. CoPA commissural axons can apparently extend normally despite not intersecting an axon of a contralateral CoPA. Micrograph showing a horizontal view of an isolated CoPA axon crossing the ventral floor of a posterior segment (S19) in a 36-hr embryo with all CoPA neurons labeled with anti-CON1. In this embryo the CoPA shown had no contralateral homologue. The embryo is slightly turned to one side. Axial muscles are seen lateral to the cord. Asterisk, Position of the CoPA cell body, which is out of focus; $C$, central canal; arrowheads, the MLF on either side of the central canal; anterior, left; scale, $50 \mu \mathrm{m}$.

cones over an extended period of development (approximately $6 \mathrm{hr}$ ), CoSA growth cones in older embryos will encounter and appear to associate with the axons of numerous nearby CoSA neurons (Fig. 12C). These data may indicate a tendency of commissural growth cones to follow other commissural axons and are consistent with the formation of spatially distinct commissural tracts in the spinal cord (Kuwada et al., unpublished observations).

\section{Discussion}

\section{Identification of CoPA and VeLD neurons during the earliest stages of axonogenesis}

The interpretation of our data depends on the identification of the CoPA and VeLD neurons at the earliest stages in their development (Kuwada et al., unpublished observations). CoPA and VeLD were identified based on the location of their somata, initial direction of the growth cones, and time of growth cone projection. CoPA neurons are the only early, dorsal neurons to project a single ventrally directed growth cone. The other 2 early, dorsal neurons (RB and DoLA) project longitudinally directed growth cones. VeLD neurons are the only early, ventral neurons to project a single ventrally directed growth cone which then turns posteriorly in the cord. The primary motor neurons are the only other neurons to begin axonogenesis in the early, ventral cord (Myers et al., 1986; Kuwada et al., unpublished observations). The VeLD neuron is distinguishable from the motor neurons, because it is located slightly dorsal to the motor neurons and by differences in the directionality of the early growth cone. The $\mathrm{CaP}$ primary motor neuron projects a ventral growth cone but it immediately exits the cord rather than turn posteriorly. The growth cones of the other 2 motor neurons (RoP and MiP) extend posteriorly in the cord for $1 / 4$ to $1 / 2$ segment before leaving the cord, but do so by projecting posteriorly directed growth cones directly from their cell bodies, several hours after the VeLD neuron. 
Figure 11. CoSA growth cone follows a pathway identical to that of CoPA growth cones, only later. Camera lucida drawings of LY-filled cells at 22, 24, and $26 \mathrm{hr}$. Scale, $50 \mu \mathrm{m}$.
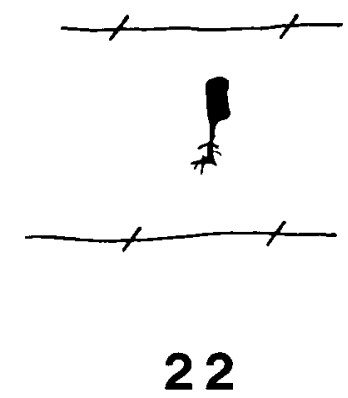
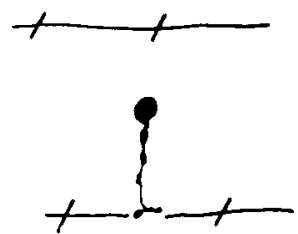

24

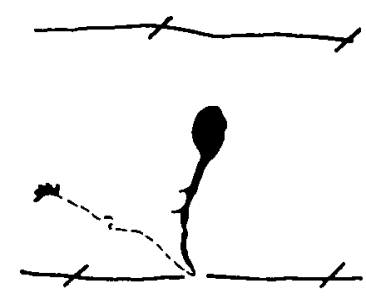

26

\section{Role of floor plate cells for axonogenesis}

Recent experiments have demonstrated that the floor plate cells can attract the growth cones of commissural neurons but apparently not other spinal neurons in the spinal cord of rat embryos (Dodd and Jessell, 1988; Tessier-Lavigne et al., 1988). In the zebrafish embryo the floor plate cells are among the earliest cells that can be identified in the spinal cord, which is the site of a number of interesting growth cone behaviors that suggest the floor plate mediates multiple, cell-specific actions on identified growth cones. (1) The floor plate cells may attract specific growth cones. The CoPA, CoSA, CoB, and VeLD growth cones, but not the RB and DoLA, are projected from the ventral pole of their somata and extend to the floor plate cells (Kuwada et al., unpublished observations). (2) The floor plate cells may induce specific growth cones to cross the ventral midline and inhibit others from doing so. Commissural growth cones cross the ventral midline by extending under the floor plate cells, but the VeLD growth cones do not cross the midline. (3) The floor plate cells may induce growth cones to make cell-specific turns. The CoPA and CoSA growth cones turn anterior, the VeLD growth cone turns posterior, and the $\mathrm{CoB}$ growth cone bifurcates. (4) The floor plate may mediate changes in the substrate affinities of growth cones. Commissural growth concs bypass longitudinal pathways before they have encountered the floor plate, but not after.

It is possible, but not likely, that other ventrally located cells may be responsible for some of these interesting growth cone behaviors. For the earliest commissural growth cones the somata of the primary motor neurons and VeLD neuron are obvious candidates for such a role (Bernhardt et al., unpublished observations). If they were involved, then one might expect these growth cones to be attracted to these cells. Apparently, this does not occur since commissural axons run to the ventral midline independently of the CaP soma and the VeLD soma. Since the 3 primary motor neurons are found in stereotyped positions in each spinal segment and commissural axons are found randomly positioned with respect to the CaP somata, it is not likely that the early commissural growth cones are attracted to the other 2 motor neurons as well.

In addition to the VeLD neurons, 2 classes of circumferential neurons have axonal trajectories which suggest that the floor plate cells may also attract their growth cones. Circumferential neurons have axons that run ventrally toward the floor plate but do not cross the midline. In the ventral cord their axons turn and ascend (CiA) or descend (CiD) (Bernhardt et al., unpublished observations).

\section{Inhibitory growth cone-substrate interactions}

Inhibition of growth cones as well as attraction of growth cones is likely to be important for guidance of growth cones (Patterson, 1988). The location of certain cells and structures in the CNS suggests that growth cones may avoid them and thereby are prevented from extending into inappropriate regions. For examplc, in the mouse optic chiasm a knot-like structure composed of glial cells may prevent retinal axons from extending into the ipsilateral optic tract (Silver, 1984). Ablation and displacement of specific peripheral structures, such as the pelvic girdle and the sclerotome cells surrounding the notochord, provide experimental evidence that structures act as barriers to extension by motor growth cones in the chick (Tosney and Landmesser, 1984; Tosney, 1988).

The inhibition of specific growth cones by the axons of certain neurons but not others has been directly observed in tissue culture (Kapfhammer et al., 1986; Kapfhammer and Raper, 1987). Here the growth cones actually collapse upon contact with certain axons and, therefore, cannot cross those axons. The behavior of the VeLD and possibly of the CiA and CiD growth cones at the floor plate suggests that the floor plate cells may prevent these growth cones from crossing the midline, possibly by contact-mediated inhibition. In fact, the proximal portion of the VeLD growth cone, which presumably is the portion of the growth cone that was initially extended toward the floor plate, remains as broad as the leading edge of the growth cone even as it is turning. This is reminiscent of filopodia that cultured growth cones will leave in contact with inhibitory axons as they are collapsing. If such inhibitory interactions occur in the zebrafish cord, they are cell-specific since other growth cones freely cross the midline.

\section{Growth cone affinities}

Since commissural growth cones appear to bypass some axons but attend to other axons, it is likely that they can distinguish among the different axons they encounter in the cord. Furthermore, the ability of growth cones to respond to specific substrates may change as the growth cone cncounters different cells and structures along its pathway. In fact, the distribution of glycoproteins on axonal surfaces is consistent with this hypothesis. The fasciclin I and II glycoproteins and the TAG-1 and L1 glycoproteins are expressed dynamically and on specific portions of the axons of certain neurons in both the insect (Bastiani et al., 1987) and mammalian (Dodd et al., 1988) CNS, respectively. Antibody perturbation experiments suggest that fasciclin 


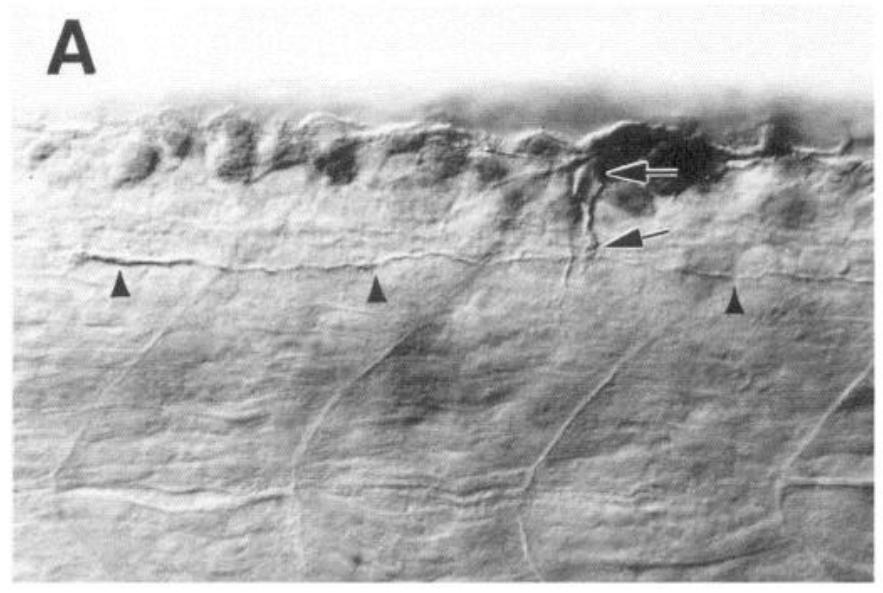

B
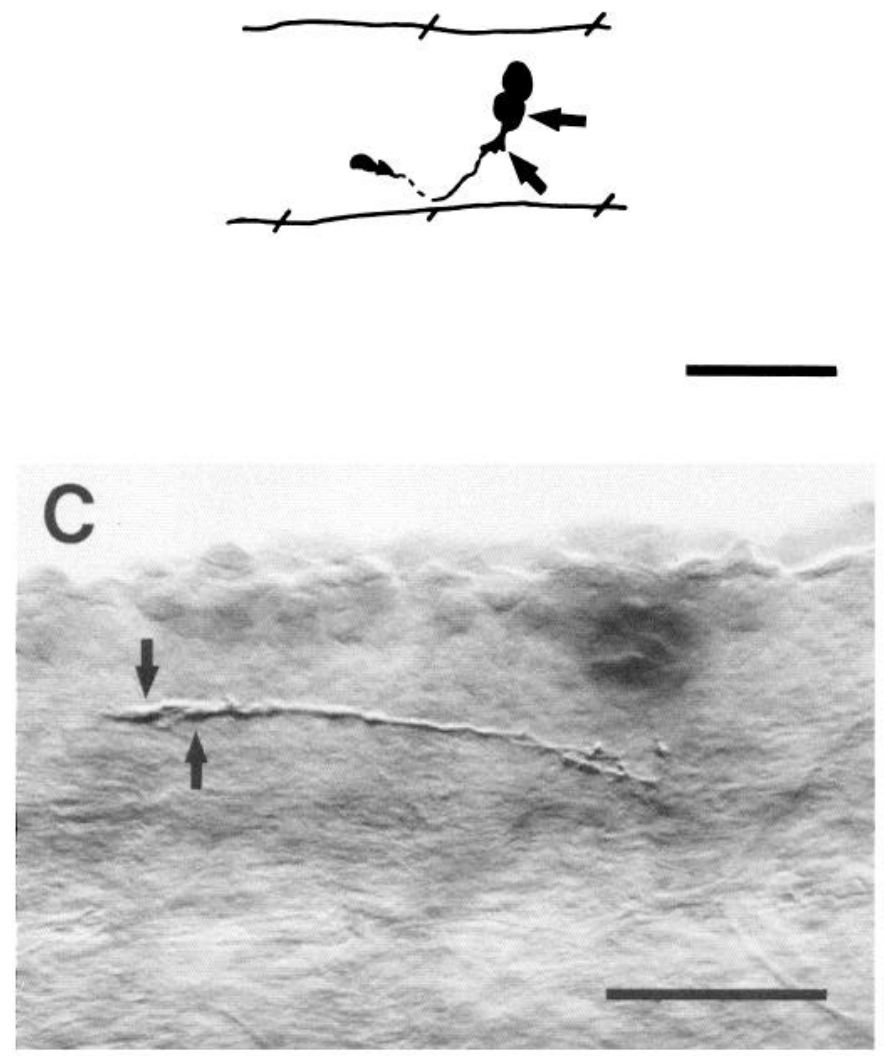

Figure 12. CoSA growth cones encounter a number of difterent axons in their environment. $A$, The growth cone (arrow) of a late-projecting CoSA neuron (arrow, cell body) encounters and presumably bypasses the axon of a contralateral CoPA neuron (arrowheads) in a 24-hr embryo. The axon of another CoSA neuron just anterior to the CoSA growth cone can be seen to cross the CoPA axon. All cells were filled with LY and labeled with anti-LY. The outlines of the axial muscle segments can be seen in the lower portion of the micrograph. $B, A$ CoSA growth cone (growth cone and cell body denoted by arrows) in close association with the axon of a CoPA neuron just dorsal to the CoSA neuron. Camera lucida drawing of LY-filled cells in a 19-hr embryo. Scale for $A$ and $B, 50 \mu \mathrm{m}$. $C$, Growth cones (arrows) of 2 adjacent CoSA neurons (somata are out of focus) extend in close association with each other. The 2 axons can be clearly distinguished on the right side of the micrograph. CoSA neurons were LY/anti-LY-labeled in a 26-hr embryo. Scale, $50 \mu \mathrm{m}$.
II (Harrelson and Goodman, 1988) and L1 (Rathjen and Schachner, 1984) are cell adhesion molecules.

The expression of affinities for different substrates at different places along the pathway may be especially important for growth cones that cross midlines like those of spinal commissural neurons. CoSA growth cones apparently turn onto the longitudinal axons of preceding commissural neurons. Many CoSA growth cones are projected when longitudinal axons of commissural neurons are already present on both sides of the cord. Despite this, the CoSA growth cones ignore the ipsilateral longitudinal axons and follow an initial circumferential pathway. Once past the ventral midline and the floor plate cells, these same growth cones turn onto the contralateral longitudinal axons of commissural neurons. The behavior of the CoSA growth cones could be accounted for if the floor plate induced an affinity by commissural growth cones for the longitudinal axons of commissural neurons. The expression of TAG-1 and L1 on commissural axons in the embryonic rat cord is especially interesting in this respect (Dodd et al., 1988). TAG-1 is expressed only on the ventrally directed portion of commissural axons while $\mathrm{L} 1$ is expressed only on the longitudinal portion of the axon. The switch from TAG-1 to L1 occurs after the axons have crossed under the floor plate.

Our descriptive study of the cells and structures encountered by identified growth cones suggests that these growth cones can distinguish among these elements. Furthermore, one of these elements, the floor plate cells, may have multiple and cell-specific effects on these identified growth cones. These hypotheses can be tested by laser ablation of floor plate cells and transplantation of floor plate cells to ectopic sites.

\section{References}

Bastiani, M. J., and C. S. Goodman (1986) Guidance of neuronal growth cones in the grasshopper embryo. III. Recognition of a specific glial pathway. J. Neurosci. 6: 3542-3551.

Bastiani, M. J., S. du Lac, and C. S. Goodman (1986) Guidance of neuronal growth cones in the grasshopper embryo. I. Recognition of a specific axonal pathway by the pCC neuron. J. Neurosci. 6: 35183531.

Bastiani, M. J., A. L. Harrelson, P. M. Snow, and C. S. Goodman (1987) Expression of fasciclin I and II glycoproteins on subsets of axon pathways during neuronal development in the grasshopper. Cell 48: 745755 .

Chitnis, A. B., and J. Y. Kuwada (1990) Axonogenesis in the brain of zebrafish embryos. J. Neurosci. (in press).

Dodd, J., and T. Jessell (1988) Axon guidance and the patterning of neuronal projections in vertebrates. Science 242: 692-699.

Dodd, J., S. B. Morton, D. Karagogeos, M. Yamamoto, and T. M. Jessell (1988) Spatial regulation of axonal glycoprotein expression on subsets of embryonic spinal neurons. Neuron 1: 105-116.

du Lac, S., M. J. Bastiani, and C. S. Goodman (1986) Guidance of neuronal growth cones in the grasshopper embryo. II. Recognition of a specific axonal pathway by the aCC neuron. J. Neurosci. 6: $3532-$ 3541 .

Eisen, J. S., P. Z. Myers, and M. Westerfield (1986) Pathway selection by growth cones of identified motoneurons in live zebrafish embryo. Nature 320: 269-271.

Eisen, J. S., S. H. Pike, and B. Debu (1989) The growth cones of identified motoneurons in embryonic zebrafish select appropriate pathways in the absence of specific cellular interactions. Neuron 2: 1097-1104.

Goodman, C. S., M. J. Bastiani, C. Q. Doe, S. du Lac, S. L. Helfand, J. Y. Kuwada, and J. B. Thomas (1984) Cell recognition during neuronal development. Science 225: 1271-1279.

Harrelson, A. L., and C. S. Goodman (1988) Growth cone guidance in insects: Fasciclin II is a member of the immunoglobulin superfamily. Science 242: 700-707.

Kapfhammer, J. P., and J. A. Raper (1987) Collapse of growth cone 
structure on contact with specific neurites in culture. J. Neurosci. 7: 201-212.

Kapfhammer, J. P., B. E. Grunewald, and J. A. Raper (1986) The selective inhibition of growth cone extension by specific neurites in culture. J. Neurosci. 6: 2527-2534.

Kuwada, J. Y. (1986) Cell recognition by neuronal growth cones in a simple vertebrate embryo. Science 233: 740-746.

Kuwada, J. Y., A. B. Chitnis, and L. A. Lindamer (1987) Stereotyped pathfinding by identified growth cones of the embryonic cord. Soc. Neurosci. Abstr. 13: 1220.

Myers, P. Z., J. Eisen, and M. Westerfield (1986) Development and axonal outgrowth of identified motoneurons in the zebrafish. $J$. Neurosci. 6: 2278-2289.

Patel, N. H., E. Martin-Blanco, K. G. Coleman, S. J. Poole, M. C. Ellis, T. B. Kornberg, and C. S. Goodman (1989) Expression of engrailed protein in arthropods, annelids, and chordates. Cell 58: 955-968.

Patterson, P. H. (1988) On the importance of being inhibited, or saying no to growth cones. Neuron 1: 263-267.

Piperno, G., and M. T. Fuller (1985) Monoclonal antibodies specific for an acetylated form of $\alpha$-tubulin recognize the antigen in cilia and flagella from a variety of organisms. J. Cell Biol. 101: 2085-2094.

Raper, J. A., M. J. Bastiani, and C. S. Goodman (1984) Pathfinding by neuronal growth cones in grasshopper embryos. IV. The effects of ablating the $A$ and $P$ axons upon the behavior of the $G$ growth cone. J. Neurosci. 4: 2339-2345.

Rathjen, F. G., and M. Schachner (1984) Immunocytological and biochemical characterization of a new neuronal cell surface component ( $\mathrm{Ll}$ antigen) which is involved in cell adhesion. EMBO J. 3: 110.

Silver, J. (1984) Studies on the factors that govern directionality of axonal growth in the embryonic optic nerve and at the chiasm of mice. J. Comp. Neurol. 223: 238-251.

Taghert, P. H., M. J. Bastiani, R. K. Ho, and C. S. Goodman (1982) Guidance of pioneer growth cones: Filopodial contacts and coupling revealed with an antibody to Lucifer Yellow. Dev. Biol. 94: 391-399.

Tessier-Lavigne, M., M. Placzek, A. G. S. Lumsden, J. Dodd, and T. M. Jessell (1988) Chemotropic guidance of developing axons in the mammalian central nervous system. Nature 336: 775-778.

Tosney, K. W. (1988) Proximal tissues and patterned neurite outgrowth at the lumbosacral level of the chick embryo: Partial and complete deletions of the somite. Dev. Biol. 127: 266-286.

Tosney, K. W., and L. T. Landmesser (1984) Pattern and specificity of axonal outgrowth following varying degrees of chick limb bud ablations. J. Neurosci. 4: 2518-2527. 